\title{
Cellular Therapies for the Treatment of Hematological Malignancies; Swine Are an Ideal Preclinical Model
}

OPEN ACCESS

Edited by: Gregers Jungersen,

Technical University of Denmark, Denmark

Reviewed by: Lawrence Schook

University of llinois at Urbana-Champaign, United States Anca Maria Cimpean, Victor Babes University of Medicine and Pharmacy, Romania

Sophie Paczesny, Indiana University Bloomington, United States

*Correspondence: Raimon Duran-Struuck rduranst@gmail.com

Specialty section: This article was submitted to Molecular and Cellular Oncology, a section of the journal Frontiers in Oncology

Received: 09 November 2018 Accepted: 02 May 2019

Published: 21 June 2019

Citation:

Duran-Struuck $R$, Huang CA and Matar AJ (2019) Cellular Therapies for the Treatment of Hematological

Malignancies; Swine Are an Ideal Preclinical Model. Front. Oncol. 9:418. doi: 10.3389/fonc.2019.00418

\author{
Raimon Duran-Struuck ${ }^{1 *}$, Christene A. Huang ${ }^{2}$ and Abraham J. Matar ${ }^{3}$ \\ ${ }^{1}$ Department of Pathobiology, University of Pennsylvania School of Veterinary Medicine, Philadelphia, PA, United States, \\ ${ }^{2}$ Department of Surgery, University of Colorado, Denver, CO, United States, ${ }^{3}$ Department of Surgery, Emory University \\ School of Medicine, Atlanta, GA, United States
}

The absence of clinically relevant large animal tumor models has historically forced experimental cellular therapies for hematological malignancies to translate directly from murine models to clinical trials. However, recent advances highlight swine as an ideal large animal model to demonstrate the safety of murine proof of concept studies prior to their implementation clinically. The availability of the MHC defined MGH miniature swine herd has been key for the development of novel approaches for hematopoietic cell and solid organ transplantation. New spontaneously arising hematological malignancies in these swine, specifically myeloid leukemias and B cell lymphomas, resemble human malignancies, which has allowed for development of immortalized tumor cell lines and has implications for the development of a large animal transplantable tumor model. The novel development of a SCID swine model has further advanced the field of large animal cancer models, allowing for engraftment of human tumor cells in a large animal model. Here, we will highlight the advantages of the swine pre-clinical model for the study of hematological malignancies. Further, we will discuss our experience utilizing spontaneously arising tumors in MGH swine to create a transplantable tumor model, describe the potential of the immunodeficient swine model, and highlight several novel cellular and biological therapies for the treatment of hematological malignancies in swine as a large animal pre-clinical bridge.

Keywords: miniature swine, lymphoma and leukemia, transplantation, cell therapy, SCID

\section{INTRODUCTION}

Preclinical murine models have long been the foundation for mechanistic studies and assessment of therapeutic strategies for human disease. While the mouse has provided a cheap, reproducible, and easy to use model whose role will never be replaced, the extrapolation of mouse studies directly to clinical application has largely been unsuccessful, especially with respect to cancer (1-3). This is likely due to the vast number of genetic, immunologic, and physiological differences between mice and humans. Murine models often recapitulate a specific pathway within a disease, but frequently do not provide the entire spectrum of physiologic changes that occur in humans, preventing direct translation of therapeutic strategies. Large animals provide a more clinically relevant model to study cancer as they are significantly more similar to humans in terms of anatomy, physiology, genetics, and immunological responses. Some however, may challenge the ethical aspects of using large animals for research purposes. Among the large animals used for pre-clinical research purposes, primates, canines, and swine are the three most common. Primates are most similar to humans 
with respect to physical and anatomic characteristics $(4,5)$, and there are an abundance of human reagents with crossreactivity to primates. However, the use of primates in research is often hindered by strict regulations, potential for communicable diseases, the requirement for significant personnel training and personal protective equipment, societal protest, and expense. Canine and swine models provide a more practical option with respect to ease of breeding and handling, shorter gestation periods, and large litters, while maintaining an anatomy and physiology that is similar to humans (6). To date, there are a limited number of large animal models of hematological malignancies $(7-10)$. However, the existing models, specifically swine models, have demonstrated that large animal hematological malignancies share important similarities to human malignancies (11-13). Further, the swine model is increasingly being used in the setting of anti-cancer drug development (14). Here we will highlight the advantages of the swine pre-clinical model for the study of hematological malignancies, while also reviewing existing swine models and exploring novel therapeutic strategies, both existing and on the horizon $(8,15)$.

\section{SWINE AS A PRECLINICAL MODEL OF MALIGNANCY}

Swine as a preclinical model of hematologic malignancy offer several advantages over other species one of which is a similar immune profile, specifically the lymphocyte repertoire. Despite the similarities, there are several important differences to note. With respect to $\mathrm{T}$ cell populations, both humans and swine possess two distinct lineages of $\mathrm{T}$ cells based on the alphabeta or gammadelta T cell receptor (16). Alphabeta T cells in both species recognize foreign antigen in an $\mathrm{MHC}$ dependent fashion, while gammadelta $\mathrm{T}$ cells recognize foreign antigen in a non-MHC dependent fashion. One major difference however is the fact that swine possess significantly higher numbers of gammadelta $\mathrm{T}$ cells than do humans, particularly in the peripheral blood and intestinal lymphoid tissues (16). Experimentally, swine alphabeta and gammadelta $\mathrm{T}$ cells can be easily distinguished based on CD3 and CD5 expression utilizing flow cytometry (Figure 1). As a result, swine represent an ideal model for the study of gammadelta $\mathrm{T}$ cell responses in the setting of malignancy, a previously underexplored area.

Both swine and humans possess traditional $\mathrm{T}$ helper cells, CD4+CD8-, which recognize antigen in a MHC class II dependent manner, and cytolytic T cells, CD4-CD8+ which recognize antigen in a MHC class I dependent manner. Swine however possess significantly more cytolytic CD8+ T cells than $\mathrm{T}$ helper CD4+ cells in circulation, which is the opposite of the human $\mathrm{T}$ cell repertoire (16). Further, while CD4+CD8+ T cells exclusively reside in the thymus in humans, CD4+CD8+ $\mathrm{T}$ cells can be found in extrathymic locations in swine, and are differentiated from $\mathrm{CD} 4+\mathrm{CD} 8+$ thymocytes by expression of CD8 alpha alpha homodimer and lack CD1 expression. Peripheral CD4+CD8 ${ }^{\text {lo }}$ cells are memory $\mathrm{T}$ helper (Th) cells, distinct from naïve Th cells which are CD4+CD8-. These

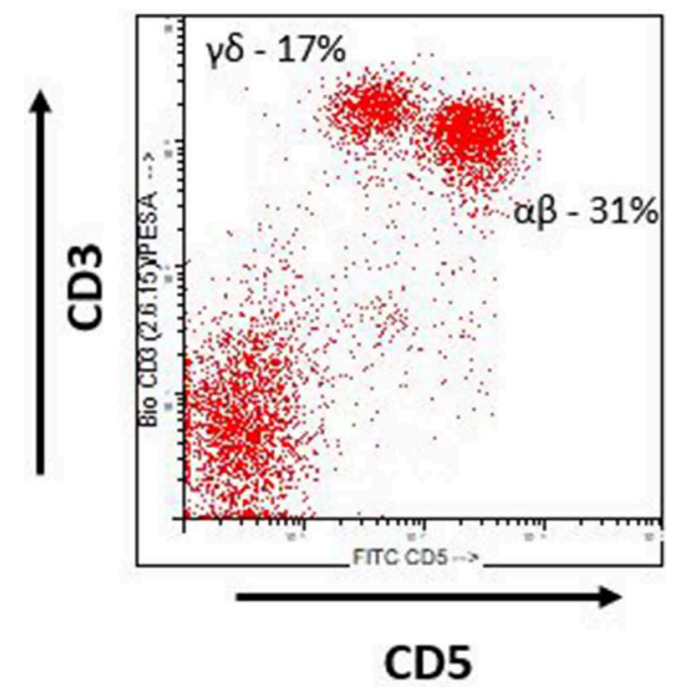

FIGURE 1 | Swine T cells. Flow cytometric analysis of swine lymphocytes from a naïve MGH miniature swine. Alphabeta $(\alpha \beta)$ and Gammadelta $(\gamma \delta)$ can easily be identified by expression of CD3 and CD5. Alphabeta T cells are CD3+ CD5 hi and Gammadelta T cells are CD3+ CD5 lo.

memory Th cells acquire the CD8 alpha alpha homodimers as a result of antigen exposure (16).

Another advantage of the swine model is the abundance of swine specific reagents available. Historically, a barrier in swine research has been the relative lack of swine specific reagents. However, a recent study outlined enormous progress on this front, specifically identifying swine cluster of differentiation (CD) markers and linking them to their human counterparts (17). A broad literature review identified 359 known swine CD markers, with over 800 identified reagents including monoclonal antibodies, polyclonal antibodies, and fusion proteins against 266 swine CD markers. With respect to in vitro monitoring of the immune system (e.g., flow cytometry), there are commercially available porcine antibodies directed against every major cell type including porcine T cells, B cells, NK cells, T regulatory cells, myeloid cells, dendritic cells, neutrophils, and others. In vivo, there are a host of swine specific reagents as previously mentioned including depleting antibodies targeted against CD3, CD4, CD8, and Tregs (17). The effects of a novel rabbit antiporcine anti-thymocyte globulin (ATG) have been investigated. Rabbit anti-human ATG is a commonly used agent clinically in the setting of conditioning prior to hematopoietic cell transplantation (HCT), treatment of graft vs. host disease (GVHD), and for treatment of acute cellular rejection after solid organ transplantation. In swine, rabbit anti-porcine ATG is a poor $\mathrm{T}$ cell depletion agent (unpublished data). In comparison, two anti-CD3 immunotoxins were superior. The chemically conjugated swine anti-CD3-immunotoxin provides robust $\mathrm{T}$ cell depletion in swine (18) while a recombinant (less toxic version) was also relatively effective with a $80 \%$ decrease in CD3 $\mathrm{T}$ cells in the peripheral blood (19). These findings have been previously documented in other species and humans supporting that monoclonal antibodies are less potent at immunodepletion 
within tissues when compared to immunotoxins (20-22). There have also been several porcine recombinant fusion toxins generated, specifically a porcine IL-2 fusion toxin for in vivo depletion of swine CD25+ cells and a porcine CTLA-4 fusion toxin for depletion of antigen presenting cells (APCs) (23). There is also evidence that human therapeutics can cross react with corresponding porcine targets in vivo with great efficacy (24).

Finally, given the recent shift in treatment of cancer toward immunotherapies, there is a growing need for new biomarkers that are predictive for treatment stratification, monitoring and response. Swine are an ideal model for the discovery and validation of novel biomarkers given their physiologic and immune similarities to humans as described previously. Advantages include the ability to longitudinally follow swine over a period of years given their long life span and the relative ease in obtaining large quantities of blood, serum, and tissue samples (25). Importantly, existing swine models of cancer have demonstrated similarities in biomarkers compared to their human counterparts. In an oncopig model of hepatocellular carcinoma (HCC), alpha feto protein (AFP) was reliably used for detection of swine HCC as well as treatment monitoring (26). With respect to hemolymphatic malignancies, in swine PTLD, LDH is a reliable marker of hemolysis and tumor development (13). The development of reliable swine models of hemolymphatic malignancies has enormous potential to uncover novel biomarkers.

\section{LARGE ANIMAL MODELS OF LYMPHOHEMATOPOIETIC MALIGNANCIES}

We previously reported our identification of spontaneously developing chronic myelogenous leukemia (CML) in the Massachusetts General Hospital (MGH) major histocompatibility complex (MHC) defined miniature swine herd (11). Through years of selective breeding, the MHC genes of these swine have been "fixed," while minor antigens remain variable, thereby providing a valuable large animal model to study transplantation. The CML that spontaneously develops in these swine (sCML) closely resembles human CML (hCML) as confirmed by flow cytometric analysis of peripheral blood mononuclear cells (PBMCs), lymph nodes (LNs), as well as histological examination of tissues obtained at necropsy (11) (Figure 2). The development of hCML is closely associated with a chromosomal translocation $t_{(9,22)}$, also known as the Philadelphia chromosome $(\mathrm{Ph}+)$ in over $95 \%$ of cases. sCML cell lines isolated from MGH miniature swine were karyotyped to evaluate for an analogous chromosomal translocation. Although the direct translation of a $t_{(9: 22)}$ translocation could not be made due to disparities in chromosome numbers (23 pairs in humans vs. 19 pairs in swine), a shortened chromosome arm was found, indicating that the development of sCML is likely associated with a chromosomal abnormality. Interestingly, sCML was associated with defects in a nucleoporin gene
(Nup107). Defects in this gene have also been associated with human leukemias $(27,28)$.

The identification of a severe combined immunodeficiency (SCID) pig at Iowa State University has offered a potentially valuable model for the study of hematological malignancies (29). These naturally occurring SCID pigs were found to have two causative mutations in the Artemis gene, a well-characterized gene in human SCID patients (30). SCID pigs share a similar immune profile to that of human SCID patients as they are completely deficient in $\mathrm{T}$ and $\mathrm{B}$ cells and are thus incapable of producing antibodies or mounting $\mathrm{T}$ cell responses. Similar to humans, the SCID pig does have macrophages and natural killer (NK) cells, the latter of which are primarily responsible for the immune response in these animals. The success of engraftment of human hematopoietic stem cells in xenotransplantation studies in mice relies, in part, on the ability of polymorphisms within the murine non-obese diabetic (NOD) signal regulatory protein alpha (SIRPA) gene that dictate its capability to be activated by human CD47 (31) on hematopietic cells. Signaling of these two molecules confers phagocytic tolerance to human stem cells by the murine monocytic/macrophage innate immune arm. Interestingly, macrophages from SCID pigs did not reject human lymphohematopoietic cells, thus demonstrating a NOD phenotype (32). However, xenogeneic tumor studies in which human pancreatic and melanoma cell lines were introduced into SCID pigs revealed an NK cell infiltrate in tumors in a subset of pigs. Despite this NK cell infiltrate, these pigs did not reject the xenografts (33). The authors hypothesized that the lack of rejection in the setting of an NK cell response was secondary to a deficiency in cytokine production, namely IL-2. Finally, Powell et al. recently reported the development of a spontaneous hostderived $\mathrm{T}$ cell lymphoma and a chronic lymphocytic leukemia (CLL) following bone marrow transplantation (BMT) in two SCID pigs (34). The development of a host-derived malignancy following BMT may be related to a "leaky" Artemis gene that allows for generation of lymphocytes, albeit at reduced numbers, as previously documented in human SCID patients (35). Moving forward, whether malignancies arise spontaneously or are introduced from allogeneic or xenogeneic origins, it is clear that the SCID pig will become a potent tool for studying lymphohematopoietic malignancies. Moreover, as the first large animal model to allow for engraftment of human cancer cell lines without concern for rejection, the SCID pig will be invaluable for testing of novel cellular and pharmacological therapies.

Previously we reported the use of the MGH miniature swine as a potential model of B cell lymphomas, specifically post-transplant lymphoproliferative disease (PTLD), which is a potentially lethal complication following transplantation $(12,36)$. In our experience with both hematopoietic cell transplantation (HCT) and solid organ transplantation (SOT), MGH miniature swine develop PTLD as a result of uncontrolled herpes viruses, either from primary infection or reactivation of a gammaherpesvirus, porcine lymphotropic herpesvirus1 (PLHV-1) (36) (Figures 3A,B). Clinically, herpes induced lymphomas (HILs) are observed in immunosuppressed patients, such as those with HIV or transplant patients. However, in humans, PTLD is driven by primary infection or reactivation 
A

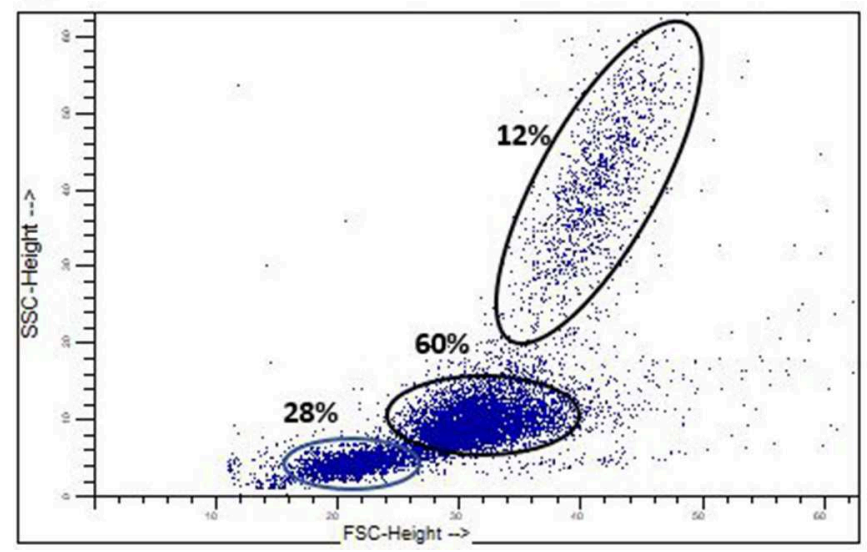

B

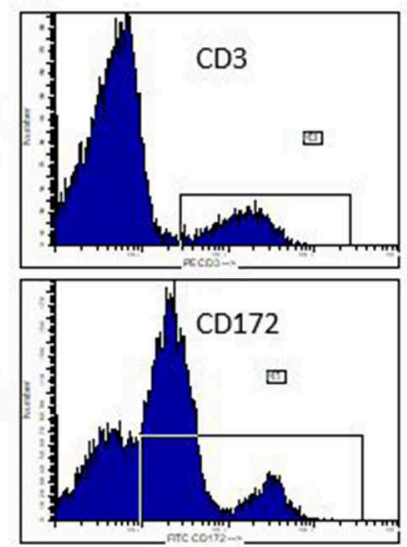

FIGURE 2 | Spontaneoulsy arising swine CML. (A) Flow cytometric analysis of peripheral blood in a swine which spontaneously developed CML, demonstrating a significant myeloblastosis. (B) CD3+ and CD172+ staining demonstrating the malignancy is of myeloid origin (CD172+) and not lymphocyte origin (CD3+).

of Epstein Barr virus (EBV) (13) as a result of loss of antiviral function of CD8+ cytotoxic $\mathrm{T}$ cells in the setting of immunosuppression. Unfortunately, there is currently no animal model that accurately recapitulates EBV-induced PTLD. To date, rodent models continue to be the most utilized when studying PTLD, with novel therapies being tested in murine xenogeneic models using human PTLDs (37). However, these rodent models cannot accurately replicate potential complications due to their small size (38). Other studies using murine gammaherpesvirus have struggled with their inaccuracy modeling human disease (38). In future studies, the SCID pig may provide an exciting model in which to study EBV driven PTLD in an animal of human size and physiology. It is important to mention that the model is not devoid of limitations. Besides the restrictions of working across xenogeneic barriers, the inherent fragility of SCID swine [which are highly susceptible to infections (35)] and the requirement of housing with room-sized specialized (Biobubbles) and hepa-filtered (ABSL-3 like) animal facilities may prove difficult to many due to expense. However, for the first time, this model will allow for the assessment of novel human derived cellular therapies and pharmacological approaches to address PTLD in a large animal model.

\section{SWINE AS A PRE-CLINICAL MODEL TO TEST BIOLOGICAL AND CELLULAR THERAPIES}

Cellular therapies such as blood transfusions have been used in medicine for decades. One of the most sophisticated cellular therapies-bone marrow transplantation (BMT)-has evolved dramatically since its inception in 1956 and is now used clinically to treat a variety of hematological malignancies and blood dyscracias (39). During BMT, the recipient's immune system is (partly or fully) destroyed by radiation or chemotherapy and replaced by either autologous or allogeneic bone marrow. Unfortunately, frequent complications

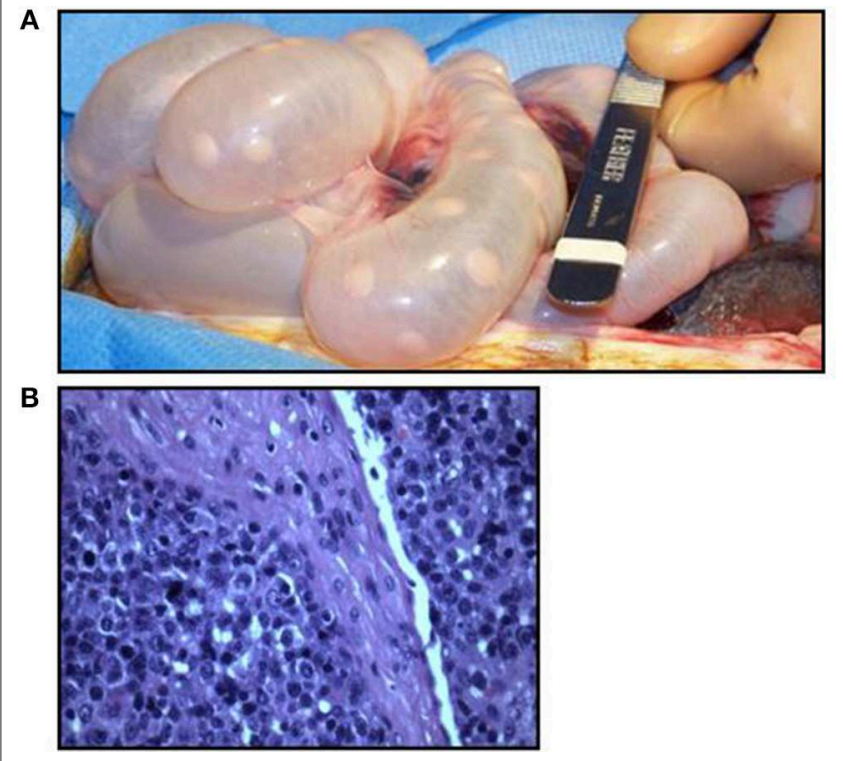

FIGURE 3 | Swine PTLD. (A) Significant intestinal lymphadenopathy in a swine with PTLD. (B) Histologic analysis of a swine intestinal lymph node demonstrating an acute lymphoblastic process in the setting of PTLD.

of allogeneic bone marrow transplantation are infection and graft-vs.-host disease (GvHD), during which donor immune cells attack recipient cells. Swine (40-42), as well as other animal models $(43,44)$, have played an important role in the study and development of BMT and other cellular therapies for clinical application. Swine are an attractive model for the study and development of cellular immunotherapies due to the abundance of swine-specific reagents available (45-52). We have previously demonstrated the applicability of swine as a clinically-relevant model for the use of cellular therapies in inducing immunological tolerance via mixed chimerism (in which both recipient and 
donor cells co-exist) as well as for the treatment of GvHD in the form of donor leukocyte infusions (DLIs) $(42,53)$. In the following, we will recap some of these studies and touch on novel cellular therapies on the horizon.

\section{Donor Leukocyte Infusions (DLI)}

The use of donor leukocyte infusions (DLI) following allogeneic HCT to both augment anti-tumor responses and enhance immune cell engraftment has expanded dramatically since its introduction 30 years ago (54). DLIs utilize donor peripheral blood leukocytes collected via apheresis, a process in which blood components are separated via density gradient and lymphocytes and monocytes are harvested, while granulocytes are returned to the patient. DLI following HCT in the setting of hematological malignancy has several indications, including as a prophylactic therapy for patients with a high risk of relapse, treatment of PTLD and viral infections and as a rescue therapy for those with graft failure. However, GVHD remains one of the most feared side effects of allogeneic BMT. Important studies by Sachs' group demonstrated the value of swine as a cell therapy model to optimize and harness the anti-leukemia effects of allogeneic HCT while avoiding GvHD. These studies in swine exploited a novel HCT approach first shown in mice in which the establishment of mixed chimerism across MHC barriers promoted immune tolerance, thus preventing $\operatorname{GvHD}(55,56)$. This study and other similar studies in non-human primates laid the foundation for Sachs' pioneering study in humans using allogeneic BMT to simultaneously treat multiple myeloma and induce immune tolerance to MHC mismatched kidney allografts (57). Using the swine model described above, we attempted to leverage the alloreactive properties of DLIs to enhance donor chimerism, thereby maintaining or preventing graft loss, while at the same time avoiding GvHD (42). In our study of a total of 33 clinically dosed DLIs infused to immune tolerant swine chimeras, 21 failed to induce conversion to full donor hematopoietic chimerism or cause GvHD, demonstrating that our reduced intensity conditioning regimen for HCT promotes mixed chimerism and an immune tolerant state that is strongly resistant to DLI and GvHD. In several animals, we were able to demonstrate that DLI mediated GvH reactivity could be overcome by significantly increasing the DLI dose, removing chimeric host peripheral blood cell populations (thought to be regulatory $\mathrm{T}$ cells) through extensive leukapheresis of the recipient immediately prior to DLI, or delivering lymphocytes fully mismatched to host MHC, but not to donor MHC. However, conversion to full donor chimerism in these scenarios was often associated with severe GvHD, highlighting the importance of mixed chimerism for maintaining immune tolerance. More refined DLIs with selected effector populations are currently being developed and swine will play an important role in determining their efficacy.

\section{$\gamma \delta$ T Cells Infusions}

$\gamma \delta \mathrm{T}$ cells are a conserved subset of $\mathrm{T}$ cells with a distinct surface receptor and which mediate innate immune responses and promote immune surveillance (58). The abundance of $\gamma \delta \mathrm{T}$ cells in humans ranges from 1 to $20 \%$ in the peripheral blood and constitutes the major cell population in skin and mucosa
(59). Swine $\gamma \delta T$ cells have been previously characterized and can be tracked in the peripheral blood and tissues using the monoclonal antibody PPT27 $(58,59) . \gamma \delta$ T cells play a known role in the anti-tumor response and can therefore potentially be used as a potent cellular therapeutic in the context of BMT. However, infusion of donor type $\gamma \delta \mathrm{T}$ cells in a murine model of acute GVHD (aGHVD) mice increased the severity of aGVHD while the absence of host type $\gamma \delta \mathrm{T}$ cells was associated with reduced antigen presenting cell (APC) activation and aGVHD in an MHC-mismatched model (59). By contrast, aGVHD severity was not altered in a MHC-matched, minor antigen (miHA) disparate model of $\operatorname{HCT}(58,60)$. Studying the role of $\gamma \delta \mathrm{T}$ cells in the setting of MHC disparity using a large animal model may prove useful amidst growing evidence of the immune modulatory effects of these cells.

$\gamma \delta \mathrm{T}$ cells provide potent anti-tumor responses to both solid and hematopoietic malignancies, including lymphoma and multiple myeloma (61). As opposed to $\alpha \beta \mathrm{T}$ cells, $\gamma \delta \mathrm{T}$ cells are not MHC restricted when it comes to antigen recognition and do not require APCs for processing immunogenic peptides, allowing them to quickly reactivate during an immune response. Interestingly $\gamma \delta \mathrm{T}$ cells can be activated and expanded in vivo through the use of bisphosphonates, which inhibit farnesyl pyrophosphate synthase (62). Taken together, the unique immune properties of $\gamma \delta \mathrm{T}$ cells, as well as their ability to be activated in vivo using conventional drugs, make them an attractive option for experimental use in swine models of HCT. Thus far, there have been limited studies utilizing $\gamma \delta \mathrm{T}$ cells in preclinical models or clinical settings. Using a large animal preclinical model such as swine, where $\gamma \delta \mathrm{T}$ cells have been well-characterized, could allow for optimization of important parameters including dosing, route (systemic vs. intratumoral), kinetics, and ex-vivo manipulation. More importantly, safety studies in an outbred swine will help discern the conflicting $\gamma \delta$ T cell GVHD murine studies and facilitate the expanded use of $\gamma \delta \mathrm{T}$ cells in clinical settings.

\section{NK Cell Therapies}

NK cells are a type of innate lymphoid cell that mount allogeneic immune responses in a non-MHC restricted manner. NK cells distinguish "self" vs. "non-self" through interactions between the killer inhibitor receptor (KIR) expressed on their surface and HLA class I expressed on the surface of host tissues. Recognition of "self" HLA class I by the KIR results in an inhibitory signal, while the absence of HLA class I expression stimulates NK cell activation. NK cells play a pivotal role in the anti-tumor response in cancer cells that down-regulate HLA expression to escape recognition by $\mathrm{T}$ cells.

Clinically, NK cells provide a powerful anti-leukemia effect in the setting of allogeneic HCT. For the treatment of acute myelogenous leukemia (AML), donor NK cell alloreactivity from KIR mismatched donors displayed an anti-leukemia effect as part of $\mathrm{T}$ cell depleted grafts, while simultaneously providing protection against GVHD (63). Based on these anti-leukemic effects in the absence of GVHD, adoptive NK cell therapy has also been studied as an alternative to unmanipulated DLI for leukemic relapse. NK-DLI was demonstrated to be both a feasible and 
safe option in a study of 30 patients receiving nonmyeloblative allogeneic stem cell transfer (SCT). CD56+ selected NK cells were given as an NK-DLI 8 weeks after initial transplant. Patients tolerated the DLI well without significant GVHD (64). In the non-transplant setting, administration of KIR mismatched NK cells in 10 pediatric patients with AML who had achieved complete remission following chemotherapy resulted in transient engraftment and excellent two year overall survival (100\%) (65). Studies are also underway to evaluate the potential for activated NK cell therapy in the setting of refractory lymphoma (66).

The recent development of the SCID pig provides an interesting avenue for studying the role of NK cells in both allogeneic and xenogeneic anti-tumor responses in a large animal model (67). Similarly to human NK cells, swine NK cells can be identified by expression of $\mathrm{CD}^{-} \mathrm{CD} 16^{+} \mathrm{CD} 56^{+}$surface markers (68). Powell et al. demonstrated that the number of NK cells in SCID pigs is approximately eight times higher than in non-SCID pigs and that these NK cells are intrinsically functional, as demonstrated by their ability to be activated in vitro and lyse tumor cells at the same rate as NK cells from non-SCID pigs (69). In the absence of circulating $\mathrm{T}$ and B cells, methods to activate and harness NK cell immune responses can be specifically evaluated in SCID pigs. For example, as IL-2 can stimulate NK cells against ovarian cancer in a murine model (70), further evaluation of IL-2 and other therapies in the SCID pig may further delineate the clinical relevance of NK cells in anti-leukemia and anti-lymphoma immune responses.

\section{Chimeric Antigen Receptor (CAR) Cells}

CARs are genetically engineered receptors that reprogram $\mathrm{T}$ cells to target specific cell surface antigens without the need for MHC interaction. CAR T cell therapy has revolutionized cancer research through the re-direction of $\mathrm{T}$ cells to target surface receptors expressed by tumor cells, most notably CD19 which is expressed on B cell malignancies (71). CAR T cells were first shown to have anti-tumor responses in mice and then in humans with refractory hematological malignancies (71-73). Currently, groups are designing novel CARs for applications other than cancer, such as autoimmunity and infectious disease (74). As a result, there is an increased need to test the safety of many of these. Indeed, fatal side-effects have been observed in clinical trials, which argues for the need for improved safety testing prior to clinical application, ideally in large animal models (75).

Given the availability of swine models of B cell lymphomas and myeloid leukemias and the identification of the SCID pig, swine may provide an ideal large animal model for the testing of CAR therapies. Though further refinement of these models is necessary, their use should be encouraged for safety assessments in pre-clinical studies. Because CARs rely on the insertion of gene sequences coding for a monoclonal antibody (with a given antigen specificity) as part of the receptor, a potential limitation of swine models is that the CAR may not recognize the target antigen on swine cells. Though this is a potential limitation, for some constructs with conserved antigens, CARs can be very informative for "off-target effects" (76). Swine may be particularly valuable for assessing the relative kinetics and persistence of individual CARs, as it was recently shown that $4-1 \mathrm{BB}$ CARs are longer lived when compared to CD28 CARs in humans (77). The potential use of SCID pigs engrafted with human leukemias/lymphomas to assess cytotoxicity/clearance, dosing, imaging, CAR surveillance and different systemic/local delivery methods may be revolutionary in a field that has been mostly limited to murine models. Furthermore, swine could also be used to test the efficacy of anti- PTLD therapies by either CARs directed to PLHV-1 in the MGH swine or to EBV CARs in the case of humanized swine. The possibilities are endless depending on the approach and research questions asked, and highlight the potential role of swine as a critical player in the pre-clinical space of cellular immunotherapies.

\section{Immune Checkpoint Blockade}

Activation of the host immune system against invading tumor cells has long been the goal of cancer therapeutics. A major breakthrough in this endeavor was the discovery of immune checkpoint proteins, which serve to downregulate the immune response. The first immune checkpoint protein to be wellcharacterized was cytotoxic T-lymphocyte-associated protein 4 (CTLA4), a receptor found on the surface of regulatory $\mathrm{T}$ cells and activated T cells. When CTLA4 is bound to its ligands, CD80 and CD86, on the surface of APCs, it provides an inhibitory signal to the $\mathrm{T}$ cell. However, the activation molecule $\mathrm{CD} 28$ also binds to CD80/CD86, albeit with a reduced affinity as compared to CTLA4. Thus, in the setting of solid organ transplantation where the goal is to suppress the host immune response to the allogeneic graft, it was hypothesized that CTLA-4 would block CD28 interactions with CD80/86, thereby preventing $\mathrm{T}$ cell activation. In support, Belatacept, a novel CTLA4 Ig fusion protein, is an effective form of immunosuppression in organ transplantation in both large animal models and humans (78, 79). Naturally, in the setting of cancer, blocking the interaction between CTLA4 and CD80/86 would serve to activate circulating $\mathrm{T}$ cells and theoretically fight off invading tumor cells. Ipilumamb, a monoclonal antibody directed against CTLA-4, was first approved by the FDA in 2011 for the treatment of metastatic melanoma and has provided excellent results (80).

The porcine version of CTLA-4 (pCTLA4) exists in several forms and can suppress human $\mathrm{CD} 4+\mathrm{T}$ cell responses costimulated by porcine B7. Utilizing a novel diptheria toxin (DT) based recombinant pCTLA4 fusion toxin, Peraino et al. demonstrated effective binding to CD80 expressing porcine cells and subsequent inhibition of protein synthesis in those cells. Follow up studies in mice inoculated with a CD80+ porcine lymphoma cell line showed that mice injected with the DT based pCTLA4 fusion toxin experienced prolonged survival compared to untreated mice. It remains to be seen whether the use of PCTLA-IT has similar effects in swine as what has been observed in murine studies where blocking or removing (genetically) host APCs diminished GVHD by limiting the direct activation of alloreactive $\mathrm{T}$ cells (81). In summary, the demonstrated ability of a DT based pCTLA4 to inhibit growth of porcine lymphoma cells provides a foundation for future work in targeting CTLA4 in large animal models of lymphohematopoietic malignancies. 


\section{CONCLUSIONS}

Cancer research is currently being revolutionized by the development of novel cellular and genetic therapies. Historically, these strategies required testing in small animals due to the absence of reliable large animal cancer models. However, recent advancements in swine including the development of immortalized myeloid and lymphoma cell lines from inbred MHC characterized swine, the accessibility of genetically engineered oncogenic swine (known as oncopigs and addressed in a companion review in this series), and the ability of engrafting human tumors in the SCID

\section{REFERENCES}

1. Mak IW, Evaniew N, Ghert M. Lost in translation: animal models and clinical trials in cancer treatment. Am J Transl Res. (2014) 6:114-8.

2. Day CP, Merlino G, Van Dyke T. Preclinical mouse cancer models: a maze of opportunities and challenges. Cell. (2015) 163:39-53. doi: 10.1016/j.cell.2015.08.068

3. Overgaard NH, Fan TM, Schachtschneider KM, Principe DR, Schook LB, Jungersen G. Of mice, dogs, pigs, and men: choosing the appropriate model for immuno-oncology research. Ilar J. (2018). doi: 10.1093/ilar/ily014. [Epub ahead of print].

4. Zitsman JS, Alonso-Guallart P, Ovanez C, Kato Y, Rosen JF, Weiner JI, et al. Distinctive leukocyte subpopulations according to organ type in cynomolgus macaques. Comp Med. (2016) 66:308-23.

5. Duran-Struuck R, Sondermeijer HP, Bühler L, Alonso-Guallart P, Zitsman $\mathrm{J}$, Kato $\mathrm{Y}$, et al. Effect of ex vivo-expanded recipient regulatory $\mathrm{t}$ cells on hematopoietic chimerism and kidney allograft tolerance across MHC barriers in cynomolgus macaques. Transplantation. (2017) 101:274-83. doi: 10.1097/TP.0000000000001559

6. Swindle MM, Makin A, Herron AJ, Clubb FJ Jr, Frazier KS. Swine as models in biomedical research and toxicology testing. Vet.Pathol. (2012) 49:344-56. doi: 10.1177/0300985811402846

7. Callesen MM, Árnadóttir SS, Lyskjaer I, Ørntoft MW, Høyer S, DagnaesHansen F, et al. A genetically inducible porcine model of intestinal cancer. Mol Oncol. (2017) 11:1616-29. doi: 10.1002/1878-0261.12136

8. Flisikowska T, Kind A, Schnieke A. Pigs as models of human cancers. Theriogenology. (2016) 86:433-7. doi: 10.1016/j.theriogenology.2016.04.058

9. Bailey KL, Carlson MA. Porcine models of pancreatic cancer. Front Oncol. (2019) 9:144. doi: 10.3389/fonc.2019.00144

10. Boettcher AN, Kiupel M, Adur MK, Cocco E, Santin AD, Bellone $\mathrm{S}$, et al. Human ovarian cancer tumor formation in severe combined immunodeficient (SCID) pigs. Front Oncol. (2019) 9:9. doi: $10.3389 /$ fonc. 2019.00009

11. Duran-Struuck R, Cho PS, Teague AG, Fishman B, Fishman AS, Hanekamp JS, et al. Myelogenous leukemia in adult inbred MHC-defined miniature swine: a model for human myeloid leukemias. Vet Immunol Immunopathol. (2010) 135:243-56. doi: 10.1016/j.vetimm.2009.12.005

12. Duran-Struuck R, Matar AJ, Huang CA. Myeloid leukemias and virally induced lymphomas in miniature inbred swine: development of a large animal tumor model. Front Genet. (2015) 6:332. doi: 10.3389/fgene.2015.00332

13. Matar AJ, Patil AR, Al-Musa A, Hanekamp I, Sachs DH, Huang CA, et al. Effect of irradiation on incidence of post-transplant lymphoproliferative disorder after hematopoietic cell transplantation in miniature swine. Biol Blood Marrow Transplant. (2015). 21:1732-8. doi: 10.1016/j.bbmt.2015.07.017

14. Mahl A, Dincer Z, Heining P. The potential of minipigs in the development of anticancer therapeutics: species comparison and examples of special applications. Toxicol Pathol. (2016) 44:391-7. doi: 10.1177/0192623315619040

15. Walters EM, Wells KD, Bryda EC, Schommer S, Prather RS. Swine models, genomic tools and services to enhance our understanding of human health and diseases. Lab Anim. (2017) 46:167-72. doi: 10.1038/ laban. 1215 pig, highlight swine as an ideal model for large animal tumor studies.

\section{AUTHOR CONTRIBUTIONS}

RD-S: Lead the topic. CH: Provided figures and edited the paper with modifications. RD-S and AM: Wrote the manuscript.

\section{FUNDING}

NIH- SERCA award- 1K01RR024466. University of Pennsylvania Internal Funds.

16. Charerntantanakul W, Roth JA. Biology of porcine T lymphocytes. Anim Health Res Rev. (2006) 7:81-96. doi: 10.1017/S1466252307001235

17. Dawson HD, Lunney JK. Porcine cluster of differentiation (CD) markers 2018 update. Res Vet Sci. (2018) 118:199-246. doi: 10.1016/j.rvsc.2018.02.007

18. Huang CA, Yamada K, Murphy MC, Shimizu A, Colvin RB, Neville DM $\mathrm{Jr}$, et al. In vivo $\mathrm{T}$ cell depletion in miniature swine using the swine CD3 immunotoxin, pCD3-CRM9. Transplantation. (1999) 68:855-60.

19. Wang Z, Duran-Struuck R, Crepeau R, Matar A, Hanekamp I, Srinivasan S, et al. Development of a diphtheria toxin based antiporcine CD3 recombinant immunotoxin. Bioconjug Chem. (2011) 22:2014-20. doi: 10.1021/bc200230h

20. Wang Z, Huang CA. A PD-1-specific toxin suppresses autoimmunity. Nat Biomed Eng. (2019) 3:253-4. doi: 10.1038/s41551-019-0384-5

21. Watanabe R, Gehad A, Yang C, Scott LL, Teague JE, Schlapbach C, et al. Human skin is protected by four functionally and phenotypically discrete populations of resident and recirculating memory T cells. Sci Transl Med. (2015) 7:279ra39. doi: 10.1126/scitranslmed.3010302

22. Wamala I, Matar AJ, Farkash E, Wang Z, Huang CA, Sachs DH. Recombinant anti-monkey CD3 immunotoxin depletes peripheral lymph node $T$ lymphocytes more effectively than rabbit anti-thymocyte globulin in naïve baboons. Transpl Immunol. (2013) 29:60-3. doi: 10.1016/j.trim.2013.10.004

23. Peraino JS, Schenk M, Li G, Zhang H, Farkash EA, Sachs DH, et al. Development of a diphtheria toxin-based recombinant porcine IL-2 fusion toxin for depleting porcine CD25+ cells. J Immunol Methods. 398-9:33-43 (2013). doi: 10.1016/j.jim.2013.09.006

24. Wang Z, Navarro-Alvarez N, Shah JA, Zhang H, Huang Q, Zheng Q, et al. Porcine Treg depletion with a novel diphtheria toxin-based antihuman CCR4 immunotoxin. Vet Immunol Immunopathol. (2016) 182:150-8. doi: 10.1016/j.vetimm.2016.10.014

25. Schachtschneider KM, Schwind RM, Newson J, Kinachtchouk N, Rizko $\mathrm{M}$, Mendoza-Elias $\mathrm{N}$, et al. The oncopig cancer model: an innovative large animal translational oncology platform. Front Oncol. (2017) 7:190. doi: $10.3389 /$ fonc. 2017.00190

26. Schachtschneider KM, Schwind RM, Darfour-Oduro KA, De AK, Rund LA, Singh K, et al. A validated, transitional and translational porcine model of hepatocellular carcinoma. Oncotarget. (2017) 8:63620-34. doi: 10.18632/oncotarget.18872

27. Takeda A, Yaseen NR. Nucleoporins and nucleocytoplasmic transport in hematologic malignancies. Semin Cancer Biol. (2014) 27:3-10. doi: 10.1016/j.semcancer.2014.02.009

28. Moore MA, Chung KY, Plasilova M, Schuringa JJ, Shieh JH, Zhou P, et al. NUP98 dysregulation in myeloid leukemogenesis. Ann N Y Acad Sci. (2007) 1106:114-42. doi: 10.1196/annals.1392.019

29. Boettcher AN, Loving CL, Cunnick JE, Tuggle CK. Development of severe combined immunodeficient (SCID) pig models for translational cancer modeling: future insights on how humanized scid pigs can improve preclinical cancer research. Front Oncol. (2018) 8:559. doi: 10.3389/fonc.2018. 00559

30. Waide EH, Dekkers JC, Ross JW, Rowland RR, Wyatt CR, Ewen CL, et al. Not All SCID pigs are created equally: two independent mutations in the artemis gene cause SCID in pigs. J Immunol. (2015) 195:3171-9. doi: 10.4049 /jimmunol.1501132 
31. Takenaka K, Prasolava TK, Wang JC, Mortin-Toth SM, Khalouei S, Gan OI, et al. Polymorphism in Sirpa modulates engraftment of human hematopoietic stem cells. Nat Immunol. (2007) 8:1313-23. doi: 10.1038/ni1527

32. Boettcher AN, Cunnick JE, Powell EJ, Egner TK, Charley SE, Loving CL, et al. Porcine signal regulatory protein alpha binds to human CD47 to inhibit phagocytosis: implications for human hematopoietic stem cell transplantation into severe combined immunodeficient pigs. Xenotransplantation. (2018). 27:e12466 doi: 10.1111/xen.12466

33. Basel MT, Balivada S, Beck AP, Kerrigan MA, Pyle MM, Dekkers JC, et al. Human xenografts are not rejected in a naturally occurring immunodeficient porcine line: a human tumor model in pigs. Biores Open Access. (2012) 1:63-68. doi: 10.1089/biores.2012.9902

34. Powell EJ, Graham J, Ellinwood NM, Hostetter J, Yaeger M, Ho CS, et al. $\mathrm{T}$ cell lymphoma and leukemia in severe combined immunodeficiency pigs following bone marrow transplantation: a case report. Frontv Immunol. (2017) 8:813. doi: $10.3389 /$ fimmu.2017.00813

35. Moshous D, Pannetier C, Chasseval Rd Rd, Deist Fl Fl, Cavazzana-Calvo M, Romana S, et al. Partial T and B lymphocyte immunodeficiency and predisposition to lymphoma in patients with hypomorphic mutations in Artemis. J Clin Invest. (2003) 111:381-7. doi: 10.1172/JCI16774

36. Doucette K, Dor FJ, Wilkinson RA, Martin SI, Huang CA, Cooper DK, et al. Gene expression of porcine lymphotrophic herpesvirus-1 in miniature Swine with posttransplant lymphoproliferative disorder. Transplantation. (2007) 83:87-90. doi: 10.1097/01.tp.0000228237.32549.16

37. Whitehurst CB, Li G, Montgomery SA, Montgomery ND, Su L, Pagano JS. Knockout of epstein-barr virus BPLF1 retards B-cell transformation and lymphoma formation in humanized mice. MBio. (2015) 6:e0157401515 doi: $10.1128 / \mathrm{mBio} .01574-15$

38. Schiffman JD, Breen M. Comparative oncology: what dogs and other species can teach us about humans with cancer. Philos Trans R Soc Lond B Biol Sci. (2015) 370:0231. doi: 10.1098/rstb.2014.0231

39. Krishnamurti L, Blazar BR, Wagner JE. Bone marrow transplantation without myeloablation for sickle cell disease. N Engl J Med. (2001) 344:68. doi: 10.1056/NEJM200101043440119

40. Sakamoto K, Pennington LR, Popitz-Bergez FA, Pescovitz MD, Gress RE, McDonough MA, et al. Swine GVHD model and the effect of T cell depletion of marrow by monoclonal antibodies. In: Gale RP, Champlin R, editors. Progress in Bone Marrow Transplantation. New York, NY: Alan R Liss (1987). p. 449-53.

41. Duran-Struuck R, Huang CA, Orf K, Bronson RT, Sachs DH, Spitzer TR. Miniature swine as a clinically relevant model of graft-versus-host disease. Comp Med. (2015) 65:429-43.

42. Duran-Struuck R, Matar AJ, Crepeau RL, Teague AGS, Horner BM, Pathiraja V, et al. Donor Lymphocyte Infusion-Mediated Graft-versus-Host Responses in a Preclinical Swine Model of Haploidentical Hematopoietic Cell Transplantation. Biol Blood Marrow Transplant. (2016) 22:1953-60. doi: 10.1016/j.bbmt.2016.08.011

43. Duran-Struuck R, Dysko RC. Principles of bone marrow transplantation (BMT): providing optimal veterinary and husbandry care to irradiated mice in BMT studies. J Am Assoc.Lab Anim Sci. (2009) 48:11-22.

44. Ladiges WC, Storb R, Thomas ED. Canine models of bone marrow transplantation. Lab Anim Sci. (1990) 40:11-15.

45. Pescovitz MD, Hsu SM, Katz SI, Lunney JK, Shimada S, Sachs DH. Characterization of a porcine CD1-specific mAb that distinguishes CD4/CD8 double-positive thymic from peripheral T lymphocytes. Tissue Antigens. (1990) 35:151-6. doi: 10.1111/j.1399-0039.1990.tb01772.x

46. Pescovitz MD, Lunney JK, Sachs DH. Preparation and characterization of monoclonal antibodies reactive with porcine PB. J Immunol. (1984) 133:368-75.

47. Pescovitz MD, Lunney JK, Sachs DH. Murine anti-swine T4 and T8 monoclonal antibodies: distribution and effects on proliferative and cytotoxic T cells. J Immunol. (1985) 134:37-44.

48. Pescovitz MD, Popitz F, Sachs DH, Lunney JK. Expression of Ia antigens on resting porcine $\mathrm{T}$ cells: a marker of functional $\mathrm{T}$ cell subsets. In: Streilein JW, Ahmad F, Black S, Blomberg B, Voellmy RW, editors. Advances in Gene Technology: Molecular Biology of the Immune System. ICSU Short Reports Vol. 2. Cambridge University Press (1985). p. 271-2.
49. Saalmüller A, Aasted B, Canals A, Dominguez J, Goldman T, Lunney JK, et al. Analyses of monoclonal antibodies reactive with porcine CD6. Vet Immunol Immunopathol. (1994) 43:243-7. doi: 10.1016/0165-2427(94)90143-0

50. Saalmüller A, Aasted B, Canals A, Dominguez J, Goldman T, Lunney JK, et al. Analyses of $\mathrm{mAb}$ reactive with porcine CD8. Vet Immunol Immunopathol. (1994) 43:249-54. doi: 10.1016/0165-2427(94)90144-9

51. Saalmüller A, Aasted B, Canals A, Dominguez J, Goldman T, Lunney JK, et al. Analyses of monoclonal antibodies reactive with porcine CD5. Vet Immunol Immunopathol. (1994) 43:237-42. doi: 10.1016/0165-2427(94)90142-2

52. Saalmüller A, Aasted B, Canals A, Dominguez J, Goldman T, Lunney JK, et al. Summary of workshop findings for porcine Tlymphocyte antigens. Vet Immunol Immunopathol. (1994) 43:219-28. doi: 10.1016/0165-2427(94)90139-2

53. Cina RA, Wikiel KJ, Lee PW, Cameron AM, Hettiarachy S, Rowland H, et al. Stable multilineage chimerism without graft versus host disease following nonmyeloablative haploidentical hematopoietic cell transplantation. Transplantation. (2006) 81:1677-85. doi: 10.1097/01.tp.0000226061. 59196.84

54. Frey NV, Porter DL. Graft-versus-host disease after donor leukocyte infusions: presentation and management. Best Pract Res Clin Haematol. (2008) 21:20522. doi: 10.1016/j.beha.2008.02.007

55. Lee PW, Cina RA, Randolph MA, Goodrich J, Rowland H, Arellano R, et al. Stable multilineage chimerism across full MHC barriers without graft-versushost disease following in utero bone marrow transplantation in pigs. Exp Hematol. (2005) 33:371-9. doi: 10.1016/j.exphem.2004.12.002

56. Hanekamp JH, Sachs DH. Chapter 23. In: McAnulty PA, Ganderup N-C, Hastings KL, editors. The Minipig in Biomedical Research. Boca Raton, FL: CRC Press (2011).

57. Kawai T, Sachs DH, Sykes M, Cosimi AB, HLA-mismatched renal transplantation without maintenance immunosuppression. $N$ Engl J Med. (2013) 368:1850-2. doi: 10.1056/NEJMc1213779

58. Nielsen MM, Witherden DA, Havran WL. gammadelta T cells in homeostasis and host defence of epithelial barrier tissues. Nat Rev Immunol. (2017) 17:733-45. doi: 10.1038/nri.2017.101

59. Vantourout P, Hayday A. Six-of-the-best: unique contributions of gammadelta T cells to immunology. Nat Rev Immunol. (2013) 13:88-100. doi: $10.1038 /$ nri3384

60. Grimm DR, Richerson JT, Theiss PM, LeGrand RD, Misfeldt ML. Isolation and characterization of gamma delta $\mathrm{T}$ lymphocyte cell lines from Sinclair swine peripheral blood. Vet Immunol Immunopathol. (1993) 38:1-20. doi: 10.1016/0165-2427(93)90110-P

61. Kunzmann V, Bauer E, Feurle J, Weissinger F, Tony HP, Wilhelm M. Stimulation of $\gamma \delta \mathrm{T}$ cells by aminobisphosphonates and induction of antiplasma cell activity in multiple myeloma. Blood. (2000) 96:384-92. Available online at: http://www.bloodjournal.org/content/96/2/384.long?ssochecked $=$ true

62. Benzaïd I, Mönkkönen H, Stresing V, Bonnelye E, Green J, Mönkkönen J, et al. High phosphoantigen levels in bisphosphonate-treated human breast tumors promote Vgamma9Vdelta2 T-cell chemotaxis and cytotoxicity in vivo. Cancer Res. (2011) 71:4562-72. doi: 10.1158/0008-5472.CAN10-3862

63. Ruggeri L, Capanni M, Urbani E, Perruccio K, Shlomchik WD, Tosti $\mathrm{A}$, et al. Effectiveness of donor natural killer cell alloreactivity in mismatched hematopoietic transplants. Science. (2002) 295:2097-100. doi: 10.1126/science. 1068440

64. Rizzieri DA, Storms R, Chen DF, Long G, Yang Y, Nikcevich DA, et al. Natural killer cell-enriched donor lymphocyte infusions from A 3-6/6 HLA matched family member following nonmyeloablative allogeneic stem cell transplantation. Biol Blood Marrow Transplant. (2010) 16:1107-14. doi: 10.1016/j.bbmt.2010.02.018

65. Rubnitz JE, Inaba H, Ribeiro RC, Pounds S, Rooney B, Bell T, et al. NKAML: a pilot study to determine the safety and feasibility of haploidentical natural killer cell transplantation in childhood acute myeloid leukemia. J Clin Oncol. (2010) 28:955-9. doi: 10.1200/JCO.2009.24.4590

66. Bachanova V, Burns LJ, McKenna DH, Curtsinger J, PanoskaltsisMortari A, Lindgren BR, et al. Allogeneic natural killer cells for refractory lymphoma. Cancer Immunol Immunother. (2010) 59:1739-44. doi: 10.1007/s00262-010-0896-Z 
67. Powell EJ, Cunnick JE, Tuggle CK. SCID pigs: an emerging large animal NK model. J Rare Dis Res Treat. (2017) 2:1-6. doi: $10.29245 / 2572-9411 / 2017 / 3.1103$

68. Gerner W, Käser T, Saalmüller A. Porcine T lymphocytes and NK cells-an update. Dev Comp Immunol. (2009) 33:310-20. doi: 10.1016/j.dci.2008.06.003

69. Powell EJ, Cunnick JE, Knetter SM, Loving CL, Waide EH, Dekkers JC, et al. NK cells are intrinsically functional in pigs with Severe Combined Immunodeficiency (SCID) caused by spontaneous mutations in the Artemis gene. Vet Immunol Immunopathol. (2016) 175:1-6. doi: 10.1016/j.vetimm.2016.04.008

70. Geller MA, Knorr DA, Hermanson DA, Pribyl L, Bendzick L, McCullar V, et al. Intraperitoneal delivery of human natural killer cells for treatment of ovarian cancer in a mouse xenograft model. Cytotherapy. (2013) 15:1297-306. doi: 10.1016/j.jcyt.2013.05.022

71. Brentjens RJ, Davila ML, Riviere I, Park J, Wang X, Cowell LG, et al. CD19-Targeted $\mathrm{T}$ cells rapidly induce molecular remissions in adults with chemotherapy-refractory acute lymphoblastic leukemia. Sci Transl Med. (2013) 5:177ra138. doi: 10.1126/scitranslmed.3005930

72. Brentjens RJ, Latouche JB, Santos E, Marti F, Gong MC, Lyddane C, et al. Eradication of systemic B-cell tumors by genetically targeted human $\mathrm{T}$ lymphocytes co-stimulated by CD80 and interleukin-15. Nat Med. (2003) 9:279-86. doi: 10.1038/nm827

73. Kalos M, Levine BL, Porter DL, Katz S, Grupp SA, Bagg A, et al. T cells with chimeric antigen receptors have potent antitumor effects and can establish memory in patients with advanced leukemia. Sci Transl Med. (2011) 3:95ra73. doi: 10.1126/scitranslmed.3002842

74. Maldini CR, Ellis GI, Riley JL. CAR T cells for infection, autoimmunity and allotransplantation. Nat Rev Immunol. (2018) 18:605-16. doi: 10.1038/s41577-018-0042-2

75. Perales MA, Kebriaei P, Kean LS, Sadelain M. Building a Safer and Faster CAR: seatbelts, airbags, and CRISPR. Biol Blood Marrow Transplant. (2018) 24:27-31. doi: 10.1016/j.bbmt.2017.10.017
76. Zhen A, Peterson CW, Carrillo MA, Reddy SS, Youn CS, Lam BB, et al. Longterm persistence and function of hematopoietic stem cell-derived chimeric antigen receptor T cells in a nonhuman primate model of HIV/AIDS. PLoS Pathog. (2017) 13:e100675. doi: 10.1371/journal.ppat.1006753

77. Kawalekar OU, O'Connor RS, Fraietta JA, Guo L, McGettigan SE, Posey AD Jr, et al. Distinct signaling of coreceptors regulates specific metabolism pathways and impacts memory development in CAR T cells. Immunity. (2016) 44:712. doi: 10.1016/j.immuni.2016.02.023

78. Vincenti F. Belatacept and long-term outcomes in kidney transplantation. $N$ Engl J Med. (2016) 374:2600-1. doi: 10.1056/NEJMc1602859

79. Lowe MC, Badell IR, Turner AP, Thompson PW, Leopardi FV, Strobert EA, et al. Belatacept and sirolimus prolong nonhuman primate islet allograft survival: adverse consequences of concomitant alefacept therapy. Am J Transplant. (2013) 13:312-9. doi: 10.1111/j.1600-6143.2012.04341.x

80. Hodi FS, O’Day SJ, McDermott DF, Weber RW, Sosman JA, Haanen JB, et al. Improved survival with ipilimumab in patients with metastatic melanoma. $N$ Engl J Med. (2010) 363:711-23. doi: 10.1056/NEJMoa1003466

81. Duran-Struuck R, Reddy P. Biological advances in acute graft-versushost disease after allogeneic hematopoietic stem cell transplantation. Transplantation. (2008) 85:303-8. doi: 10.1097/TP.0b013e318162d357

Conflict of Interest Statement: The authors declare that the research was conducted in the absence of any commercial or financial relationships that could be construed as a potential conflict of interest.

Copyright (c) 2019 Duran-Struuck, Huang and Matar. This is an open-access article distributed under the terms of the Creative Commons Attribution License (CC BY). The use, distribution or reproduction in other forums is permitted, provided the original author(s) and the copyright owner(s) are credited and that the original publication in this journal is cited, in accordance with accepted academic practice. No use, distribution or reproduction is permitted which does not comply with these terms. 